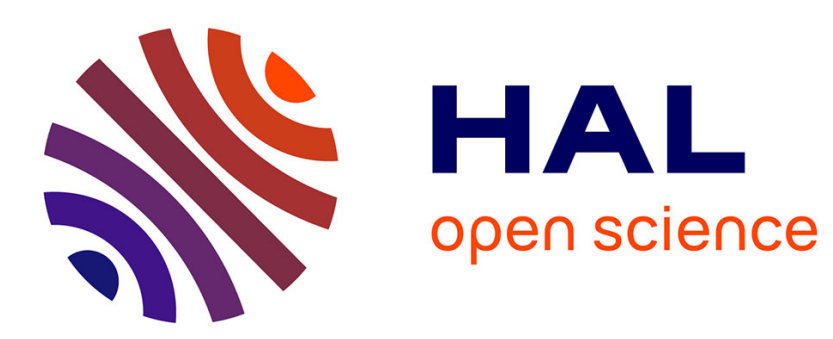

\title{
A generalized lateral interactions function to fit voltammetric peaks of self-assembled monolayers
}

Olivier Alévêque, Eric Levillain

\section{To cite this version:}

Olivier Alévêque, Eric Levillain. A generalized lateral interactions function to fit voltammetric peaks of self-assembled monolayers. Electrochemistry Communications, 2016, 67, pp.73-79. 10.1016/j.elecom.2016.04.003 . hal-01309455v2

\section{HAL Id: hal-01309455 \\ https://hal.science/hal-01309455v2}

Submitted on 25 Oct 2019

HAL is a multi-disciplinary open access archive for the deposit and dissemination of scientific research documents, whether they are published or not. The documents may come from teaching and research institutions in France or abroad, or from public or private research centers.
L'archive ouverte pluridisciplinaire HAL, est destinée au dépôt et à la diffusion de documents scientifiques de niveau recherche, publiés ou non, émanant des établissements d'enseignement et de recherche français ou étrangers, des laboratoires publics ou privés. 


\section{Accepted Manuscript}

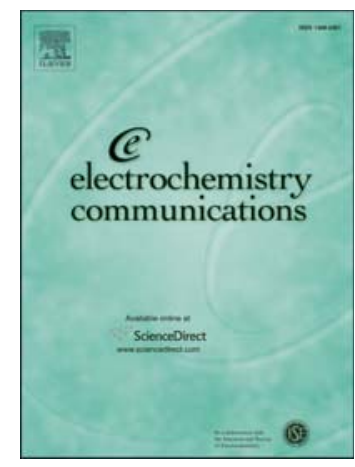

A generalized lateral interactions function to fit voltammetric peaks of self-assembled monolayers

Olivier Alévêque, Eric Levillain

PII:

DOI:

S1388-2481(16)30078-9

Reference: $\quad$ ELECOM 5676

To appear in: $\quad$ Electrochemistry Communications

Received date: 9 March 2016

Revised date: $\quad 4$ April 2016

Accepted date: 5 April 2016

Please cite this article as: Olivier Alévêque, Eric Levillain, A generalized lateral interactions function to fit voltammetric peaks of self-assembled monolayers, Electrochemistry Communications (2016), doi: 10.1016/j.elecom.2016.04.003

This is a PDF file of an unedited manuscript that has been accepted for publication. As a service to our customers we are providing this early version of the manuscript. The manuscript will undergo copyediting, typesetting, and review of the resulting proof before it is published in its final form. Please note that during the production process errors may be discovered which could affect the content, and all legal disclaimers that apply to the journal pertain. 
A generalized lateral interactions function to fit voltammetric peaks of self-assembled monolayers

Olivier Alévêque* and Eric Levillain

Université d'Angers, CNRS UMR 6200, Laboratoire MOLTECH-Anjou, 2 bd Lavoisier, 49045 ANGERS cedex, France.

* Corresponding authors: Tel.: (+33)241735090; Fax: $(+33) 241735405$

E-mail address: olivier.aleveque@univ-angers.fr (Olivier ALEVEQUE)

\begin{tabular}{l|l}
\hline ARTICLE INFO & ABSTRACT \\
\hline $\begin{array}{l}\text { Keywords: } \\
\text { Self-assembled monolayers } \\
\text { Cyclic voltammetry }\end{array}$ & $\begin{array}{l}\text { From the generalized lateral interactions model and via a few mathematical approximations, } \\
\text { a suitable regression function has been developed in order to fit voltammetric peak of redox } \\
\text { Lateral interactions }\end{array}$ \\
Curve fitting & gesponsive SAM for extracting the characteristic parameters. The efficiency of the \\
\hline
\end{tabular}

\section{Introduction}

Since their initial discovery in 1946 [1], self-assembled monolayers (SAMs) have become an ideal system for the theoretical study of interfacial phenomena, especially in the field of electrochemistry when they are immobilized on conductive substrates like gold [2,3]. A major constraint to obtain a fine characterisation of electroactive SAMs is the dispersion of the current-voltage characteristics around the fully solved theoretical one [4]. Indeed, cyclic voltammograms (CVs) of SAMs are most often complex with sharper or broader voltammetric peaks than in the ideal case [5-8].

Some of these electrochemical behaviours can be explained by several theories/models, like the generalized lateral interactions model (GLI model) [7]. They allow to clarify deviations from ideality and define characteristic parameters of theoretical voltammograms like peak potential $\left(E_{p}\right)$, peak intensity $\left(i_{p}\right)$ and full width at half maximum (FWHM) in the case of infinite electron transfer.

However, using the GLI model to perform a global fit of experimental CVs is impossible, because the expression of I-V curves leads to a recursive function, excluding a curve fitting analysis.

A first alternative to analyse CV peaks consists in using the graphical analysis tools of the commercial instrument control software. This method allows determining characteristic parameters $\left(E_{p}, i_{p}\right.$ and $\left.F W H M\right)$ of the CVs but do not allow determining if a particular experimental profile follows a theoretical curve. 
A second alternative, detailed in previous work, proposed to fit CV peaks via usual or unusual functions [9, 10] such as Gaussian [11-13], Lorentzian [11-13], or Generalized Gaussian Function [14] but these calculations were either very complex or not based on a theoretical support.

Herein, we propose a regression function, derived from the GLI model [6], which allows extracting characteristic parameters of a voltammetric peak and interaction constants of an electroactive system by curve fitting.

\section{The GLI model}

In previous works, we presented theoretical studies to complete the lateral interaction model proposed by $\mathrm{E}$. Laviron [5], by extending this initial model to non-random distributions of electroactive species and by taking into account the interactions between redox and non-redox species [7].

In the case of interactions between redox species only, this model enables current-voltage behaviours to be simulated and allows extracting characteristics parameters of CVs obtained from any surface distribution of electroactive SAM.

For a better reading of the article, we must summarize previous works.

The generalized lateral interactions model can be defined according to the main following hypotheses:

- The electroactive species are distributed on substrate with a unimodal statistical distribution of electroactive neighbours. A parameter $\phi(\theta)$, between 0 and 1, defined for a normalized surface coverage $\theta=\frac{\Gamma}{\Gamma_{\max }}$, quantifies the segregation level of the electroactive species. For a randomly distributed SAM, $\phi(\theta)=\theta$, and when a segregation exists on the surface, $\phi(\theta)>\theta$,

- The sum of normalized surface coverage $\theta_{\circ}$ and $\theta_{R}$ of oxidized $(O)$ and reduced $(R)$ species is constant and equal to $\theta$,

- The surface occupied by one molecule of $O$ is equal to the surface occupied by one molecule of $R$,

- The electrochemical rate constant $k_{s}$ is independent of the coverage,

- $\mathrm{a}_{\mathrm{OO}}, \mathrm{a}_{\mathrm{RR}}$ and $\mathrm{a}_{\mathrm{OR}}$ are the interaction constants between molecules of $\mathrm{O}$, molecules of $\mathrm{R}$ and molecules of $O$ and $R$, respectively. $a_{i j}$ is positive for an attraction and negative for a repulsion.

For a full reversible reaction $\left(\frac{\mathrm{k}_{\mathrm{s}}}{\mathrm{V}} \rightarrow \infty\right)$, CVs are perfectly reversible and the current can be expressed as a function of $\theta_{\circ}$ : 
$\mathrm{i}\left(\theta_{\mathrm{O}}\right)=\frac{\mathrm{n}^{2} \mathrm{~F}^{2} A v \Gamma_{\max }}{\mathrm{RT}} \frac{\theta_{\mathrm{O}}\left(\theta-\theta_{\circ}\right) \theta}{\theta^{2}-2 \mathrm{G} \theta_{\circ} \phi(\theta)\left(\theta-\theta_{\circ}\right)}$

The characteristic parameters of CVs as full width at half maximum (FWHM), peak potential $\left(\mathrm{E}_{\mathrm{p}}\right)$ and peak current $\left(i_{p}\right)$ can be extracted and defined as:

$\mathrm{E}_{\mathrm{p}}(\phi(\theta))=\mathrm{E}_{0}^{\prime}+\frac{\mathrm{RT}}{\mathrm{nF}} \mathrm{S} \phi(\theta)$

$\mathrm{FWHM}(\phi(\theta))=\frac{2 \mathrm{RT}}{\mathrm{nF}}\left[\ln \left(\frac{1+\sqrt{\frac{2-\mathrm{G} \phi(\theta)}{4-\mathrm{G} \phi(\theta)}}}{1-\sqrt{\frac{2-\mathrm{G} \phi(\theta)}{4-\mathrm{G} \phi(\theta)}}}\right)-\mathrm{G} \phi(\theta) \sqrt{\frac{2-\mathrm{G} \phi(\theta)}{4-\mathrm{G} \phi(\theta)}}\right] \stackrel{\operatorname{G\phi }(\theta)<1 \mid}{\approx} \frac{\mathrm{RT}}{\mathrm{nF}}\left(2 \ln (2 \sqrt{2}+3)-\frac{3 \sqrt{2}}{2} \mathrm{G} \phi(\theta)\right)$

$\mathrm{i}_{\mathrm{p}}(\theta, \phi(\theta))=\frac{\mathrm{n}^{2} \mathrm{~F}^{2} \mathrm{vA} \Gamma_{\max }}{\mathrm{RT}} \frac{\theta}{2(2-\mathrm{G} \phi(\theta))}$

With $n, F, v, A, R, T, E, E_{0}^{\prime}$ have their usual meanings

And $\mathrm{G}=\mathrm{a}_{\mathrm{OO}}+\mathrm{a}_{\mathrm{RR}}-2 \mathrm{a}_{\mathrm{OR}}$ and $\mathrm{S}=\mathrm{a}_{\mathrm{RR}}-\mathrm{a}_{\mathrm{OO}} \quad$ with $\quad|\mathrm{G}|$ and $|\mathrm{S}| \leq 2$

$\mathrm{G}$ and $\mathrm{S}$ are defined as "global interaction" parameters and play an important role when associated with $\phi(\theta)$. Indeed, $G \cdot \phi(\theta)$ defines the shape of the peak and modulates the FWHM and the peak intensity $\left(\mathrm{i}_{p}\right)$, wheareas $S \cdot \phi(\theta)$ only defines the position of the peak potential $\left(E_{p}\right)$.

\section{The generalized lateral interactions function (GLI function)}

\subsection{Introduction to the GLI function}

The GLI model is very useful to predict characteristic parameters of CVs but, in order to fit CVs, and contrary to the expression 1, the current needs to be expressed as a function of the applied potential (E).

For a fast reversible system $\left(\frac{\mathrm{k}_{\mathrm{s}}}{\mathrm{v}} \rightarrow \infty\right)$ the Nernst equation is applicable using surface activity of the two redox species [6]:

$\frac{\gamma_{O}}{\gamma_{R}}=\exp \left[\frac{n F}{R T}\left(E-E_{0}^{\prime}\right)\right]=\frac{\theta_{O}}{\theta-\theta_{O}} \exp \left[-2 \frac{\phi(\theta)}{\theta}\left(G \theta_{O}+\theta\left(a_{O R}-a_{R R}\right)\right)\right]$

This expression directly links the applied potential with the normalized surface coverage of oxidized species $\left(\theta_{\mathrm{O}}\right)$ and interaction parameters $\left(\mathrm{G}, \mathrm{a}_{\mathrm{OO}}\right.$ and $\left.\mathrm{a}_{\mathrm{OR}}\right)$.

From the equations $\mathbf{2}$ and $\mathbf{5}$, it is possible to optimise this expression in order to limit the number of unknown parameters: 
$\frac{\mathrm{nF}}{\mathrm{RT}}\left(\mathrm{E}-\mathrm{E}_{\mathrm{p}}\right)=\ln \left(\frac{\theta_{\mathrm{O}}}{\theta-\theta_{\mathrm{O}}}\right)-2 \mathrm{G} \frac{\phi(\theta)}{\theta} \theta_{\mathrm{O}}+\mathrm{G} \phi(\theta)$

$\frac{\theta_{\mathrm{O}}}{\theta-\theta_{\mathrm{O}}}=\exp \left(\frac{\mathrm{nF}}{\mathrm{RT}}\left(\mathrm{E}-\mathrm{E}_{\mathrm{p}}\right)+2 \mathrm{G} \frac{\phi(\theta)}{\theta} \theta_{\mathrm{O}}-\mathrm{G} \phi(\theta)\right)=\exp (\mathrm{X})$

with $X=\frac{n F}{R T}\left(E-E_{p}\right)+2 G \frac{\phi(\theta)}{\theta} \theta_{O}-G \phi(\theta)$

and $\left\{\begin{array}{l}\theta_{\mathrm{O}}=\theta \frac{\exp \left(\frac{\mathrm{nF}}{\mathrm{RT}}\left(\mathrm{E}-\mathrm{E}_{\mathrm{p}}\right)+2 \mathrm{G} \frac{\phi(\theta)}{\theta} \theta_{\mathrm{O}}-\mathrm{G} \phi(\theta)\right)}{1+\exp \left(\frac{\mathrm{nF}}{\mathrm{RT}}\left(\mathrm{E}-\mathrm{E}_{\mathrm{p}}\right)+2 \mathrm{G} \frac{\phi(\theta)}{\theta} \theta_{\mathrm{O}}-\mathrm{G} \phi(\theta)\right)}=\theta \frac{\exp (\mathrm{X})}{1+\exp (\mathrm{X})}=\frac{\theta}{1+\exp (-\mathrm{X})} \\ \theta_{\mathrm{R}}=\theta \frac{1}{1+\exp \left(\frac{\mathrm{nF}}{\mathrm{RT}}\left(\mathrm{E}-\mathrm{E}_{\mathrm{p}}\right)+2 \mathrm{G} \frac{\phi(\theta)}{\theta} \theta_{\mathrm{O}}-\mathrm{G} \phi(\theta)\right)}=\frac{\theta}{1+\exp (\mathrm{X})}\end{array}\right.$

From the equations $\mathbf{1}$ and $\mathbf{8}$, the current can be expressed with the $X$ variable:

$\mathrm{i}(\mathrm{X})=\frac{\mathrm{n}^{2} \mathrm{~F}^{2} \mathrm{Av} \Gamma_{\max } \theta}{\mathrm{RT}} \frac{\exp (\mathrm{X})}{(1+\exp (\mathrm{X}))^{2}-2 \mathrm{~B} \exp (\mathrm{X})}$

With $\mathrm{B}=\mathrm{G} \phi(\theta)$ an interaction constant, and $|\mathrm{B}|<2$.

To finalize the regression function, $X$ needs to be expressed as a function of the applied potential. By combining expressions 7 and 8 :

$\mathrm{X}=\frac{\mathrm{nF}}{\mathrm{RT}}\left(\mathrm{E}-\mathrm{E}_{\mathrm{p}}\right)+2 \mathrm{G} \frac{\phi(\theta)}{\theta} \theta_{\mathrm{O}}-\mathrm{G} \phi(\theta)=\frac{\mathrm{nF}}{\mathrm{RT}}\left(\mathrm{E}-\mathrm{E}_{\mathrm{p}}\right)+2 \mathrm{~B} \frac{\theta_{\mathrm{O}}}{\theta}-\mathrm{B}$

$\mathrm{X}=\frac{\mathrm{nF}}{\mathrm{RT}}\left(\mathrm{E}-\mathrm{E}_{\mathrm{p}}\right)+\frac{2 \mathrm{~B}}{1+\exp (-\mathrm{X})}-\mathrm{B}$

Equation 10 shows that the variable $\mathrm{X}$ is recursive, i.e. it is defined as a function of itself.

\subsection{Approximation of the $X$ variable and definition of GLI function}

To circumvent the problem of recursion, an approximation of the expression $\left(2 \mathrm{~B} \frac{\theta_{\mathrm{O}}}{\theta}=\frac{2 \mathrm{~B}}{1+\exp (-\mathrm{X})}\right)$ included in the equation 10 must be determined. To achieve this, a set of simulations with different values of $\mathrm{B}$ was performed. To illustrate simulations, Figure $1 \mathrm{~A}$ represents the dimensionless simulated current 
$\Psi=\frac{\mathrm{i}}{\left(\frac{\mathrm{n}^{2} \mathrm{~F}^{2} \mathrm{Av} \Gamma_{\max } \theta}{\mathrm{RT}}\right)}$ of a SAM using $\mathrm{B}=0.8$, and Figure 1B the different components of the variable $\mathrm{X}$ $\left(X=X a+X b+X c ; X a=\frac{n F}{R T}\left(E-E_{p}\right) ; X b=\frac{2 B}{1+\exp (-X)} ; X c=B\right)$.

By definition, component $\mathrm{Xb}$ is a perfect sigmoid as a function of $\mathrm{X}$ but not as a function of $\mathrm{E}$. However, by a moderate approximation of $\mathrm{X}$ in $\mathrm{Xb}$ expression, it is possible to fit $\mathrm{Xb}$ according to $\mathrm{E}$ by a generalized sigmoid (Figure 1C):

$$
\mathrm{Xb}_{\mathrm{fit}}=\frac{2 \mathrm{~B}}{1+\exp \left(-\frac{\mathrm{nF}}{\mathrm{RT}}\left(\mathrm{E}-\mathrm{E}_{\mathrm{p}}\right) \lambda\right)} \quad \text { with } \mathrm{X}=\frac{\mathrm{nF}}{\mathrm{RT}}\left(\mathrm{E}-\mathrm{E}_{\mathrm{p}}\right) \lambda
$$

$\lambda$ parameter allows modulation of the slope at the inflection point and is only B dependant (Figure 1D), the inverse of $\lambda$ being perfectly proportional to $B$ :

$\frac{1}{\lambda}=1-\gamma \cdot \mathrm{B} \quad$ with $\gamma=0.399 \pm 0.001 \approx 0.4$ when $\mathrm{B}<|2|$

To conclude, the GLI function can be expressed as a function of the applied potential by combining the equations $9,10,11$ and 12 :

$\mathrm{i}(\mathrm{E})=\frac{\mathrm{n}^{2} \mathrm{~F}^{2} \mathrm{Av}}{\mathrm{RT}} \frac{\Gamma \exp (\mathrm{X})}{(1+\exp (\mathrm{X}))^{2}-2 \mathrm{~B} \exp (\mathrm{X})}$

with $\left\{\begin{array}{l}X=\frac{n F}{R T}\left(E-E_{p}\right)+\frac{2 B}{1+\exp \left(-\frac{n F}{R T} \frac{\left(E-E_{p}\right)}{(1-\gamma \cdot B)}\right)}-B \\ \gamma=0.4 \\ B=G \phi(\theta) \text { and }|B|<2\end{array}\right.$

And $\mathrm{E}_{\mathrm{p}}, \mathrm{B}$ and $\Gamma\left(\Gamma=\Gamma_{\max } \theta\right)$ are the unknow parameters of the fit

\subsection{Determination of characteristic parameters of fitted CVS}

Peak potential $\left(E_{p}\right)$ is directly determined by the fit of experimental CVs:

$\mathrm{E}_{\mathrm{p}} \pm \sigma_{\mathrm{E}_{\mathrm{p}}}$

Peak intensity $\left(i_{p}\right)$ can be extracted easily with the equation 13 : 


$$
\begin{aligned}
& i_{p}=i\left(E=E_{p} \text { or } X=0\right)=\frac{n^{2} F^{2} A v}{R T} \frac{\Gamma}{4-2 B} \\
& \sigma_{i_{p}}=\frac{n^{2} F^{2} A v}{R T} \sqrt{\left(\frac{1}{4-2 B} \sigma_{\Gamma}\right)^{2}+\left(\frac{2 \Gamma}{(4-2 B)^{2}} \sigma_{B}\right)^{2}}
\end{aligned}
$$

An approximation of FWHM can be deduced at $\frac{\mathrm{i}_{\mathrm{p}}}{2}$ from equations 9 and 11 (see Appendix):

$$
\begin{aligned}
& \mathrm{FWHM}=\mathrm{E}_{+}-\mathrm{E}_{-}=2 \frac{\mathrm{RT}}{\mathrm{nF} \lambda} \ln \left(\frac{1+\sqrt{\frac{\mathrm{B}-2}{\mathrm{~B}-4}}}{1-\sqrt{\frac{\mathrm{B}-2}{\mathrm{~B}-4}}}\right)=2 \frac{\mathrm{RT}}{\mathrm{nF}}(1-\gamma \mathrm{B}) \ln \left(\frac{1+\sqrt{\frac{\mathrm{B}-2}{\mathrm{~B}-4}}}{1-\sqrt{\frac{\mathrm{B}-2}{\mathrm{~B}-4}}}\right) \\
& \sigma_{\mathrm{FWHM}}=2 \frac{\mathrm{RT}}{\mathrm{nF}}\left(\gamma \ln \left(\frac{1+\sqrt{\frac{\mathrm{B}-2}{\mathrm{~B}-4}}}{1-\sqrt{\frac{\mathrm{B}-2}{\mathrm{~B}-4}}}\right)+\frac{2(1-\gamma \mathrm{B})}{(\mathrm{B}-4)^{2} \sqrt{\frac{\mathrm{B}-2}{\mathrm{~B}-4}}\left(1+\sqrt{\frac{\mathrm{B}-2}{\mathrm{~B}-4}}\right)\left(1-\sqrt{\frac{\mathrm{B}-2}{\mathrm{~B}-4}}\right)}\right) \sigma_{\mathrm{B}}
\end{aligned}
$$

It is noteworthy that the GLI function gives access to some physico-chemical characteristics, unlike usual functions. With GLI function, surface coverage $(\Gamma)$ and the interaction constant B are directly determined by the fit of experimental CVs:

$\Gamma \pm \sigma_{\Gamma} \quad$ and $\quad \mathrm{B} \pm \sigma_{\mathrm{B}}$

\section{Discussions}

\subsection{Ideal case}

In the ideal case of immobilized electroactive centers (i.e. Langmuir model where all adsorption sites are equivalent and there is no intersite interaction), CVs shape are independent of the surface coverage and can be described by the algebraic equation formulated by Laviron [5]:

$$
\mathrm{i}(\mathrm{E})=\frac{\mathrm{n}^{2} \mathrm{~F}^{2} \mathrm{~A} v \Gamma}{\mathrm{RT}} \frac{\mathrm{e}^{\left(\frac{\mathrm{nF}}{\mathrm{RT}}\left(\mathrm{E}-\mathrm{E}_{0}^{\prime}\right)\right)}}{\left(1+\mathrm{e}^{\left(\frac{\mathrm{nF}}{\mathrm{RT}}\left(\mathrm{E}-\mathrm{E}_{0}^{\prime}\right)\right)}\right)^{2}}
$$

It is worth noting that for $B=0$ (i.e. ideal case), the GLI function (Eq. 13) simplifies into an expression similar to the Laviron case (Eq. 18), i.e. the ideal case is natively a particular case of the GLI function. 


\subsection{GLI function vs. generalized lateral interactions model}

To test the reliability of the GLI function in controlled conditions, a set of CVs was simulated in the case of phase segregation $(\phi(\theta)>\theta)$ for two significant values of $G$ parameter (i.e. $G= \pm 1$ ) and fitted with the GLI function in order to extract characteristic parameters $\left(E_{p}, i_{p}, F W H M, \Gamma\right.$ and $\left.G \phi(\theta)\right)$. These parameters were then plotted versus the theoretical surface coverage $\Gamma$ and compared to the theoretical values from the GLI model (Figure 2 and Figure 3).

As expected, the agreement between the simulated voltammetry peaks and the fitted curves in the two borderline cases of phase segregation provides evidence of the usefulness of the GLI function. All characteristic parameters fit with the theoretical ones in a wide range of surface coverage. Even the approximate function (Eq. 16) to calculate the FWHM allows, compared to a graphic determination, obtaining a good estimate of this parameter. It is noteworthy a good agreement of the regression analysis in the difficult case of narrow peaks (i.e. $G>0$ ) compared to previous works where sharp peaks and discontinuities are observed.

\subsection{GLI function vs. experimental voltammograms}

We confronted the GLI function to experimental CVs of TTF SAMs [15]. This well-known system presents two successive oxidations, and thus makes the linearization procedure more difficult.

The major difficulty which can disturb the performance of curve fitting processes is the non-predictable trend of experimental CV baseline. To circumvent this problem, a monotonic polynomial function (i.e. $\left.g(x)= \pm \sum_{i=0}^{n}\left|a_{i} \cdot x^{i}\right|\right)$ was added to functions.

An important hypothesis is that charges involved must be conserved during the two successive oxidations of TTF molecules, so this point is imposed on the fitting procedure.

Figure $4 \mathrm{~A}$ shows that GLI function is able to extract all components of the experimental CV. As expected, the charge of each oxidation process is conserved and the two successive voltammetry peaks are consistent with GLI model and present repulsive and attractive interactions, respectively.

The regression analysis from GLI function was then compared to previous work performed with a Generalized Gaussian function (GG function) on CV of TTF SAM (Figure 4B) [14]. As anticipated, no difference is observed on the first oxidation step because the peak is rather broad. By contrast, the narrowness of the second peak allows assessment of the quality of the regression analysis via the GLI 
function, compared to GG function which produces a sharp peak not consistent with raw data. This difference is because GLI function is not empiric but is based on a model that leads the voltammetric shape. To support that, we confronted the GLI function to experimental CVs of TEMPO SAMs, a redox-responsive material well-known for its strong attractive interactions $(\mathrm{G}>0)$ between oxidized species in $\mathrm{CH}_{2} \mathrm{Cl}_{2}[6]$. Figure 4C and 4D show a real difference between the two fitting curves despite the correlation coefficients being rather close. Once again, the GLI function fits the shape of the experimental curves and allows extracting the characteristic parameters of CVs, with good accuracy.

Note that with good initial values of $\left(E_{p}, B\right.$ and $\left.\Gamma\right)$, the fitting procedure from GLI function rapidly converges and reaches an absolute minimum.

\section{Conclusion}

Derived from the GLI model, a regression function has been developed and tested on simulated and raw data in order to fit voltammetric peak of self-assembled monolayers for extracting easily characteristic parameters such as the full width at half maximum, the peak potential and the peak current.

Furthermore, the GLI function gives access to some physico-chemical characteristics such as surface coverage and interaction constant, unlike the usual functions.

This work reinforces the idea that a regression function derived from a theoretical model is more suitable to fit raw data than an empirical function like Gaussian, Generalised Gaussian, Lorentzian and Extreme functions.

\section{Acknowledgments}

All fitting procedures were performed with SigmaPlot ${ }^{\mathrm{TM}}$ 13. All simulations were performed with $\mathrm{C}_{++}$ programs. The authors thank Flavy Alévêque for her critical reading of the manuscript. 


\section{Appendix}

\section{FWHM approximation}

FWHM cannot be extracted at $\frac{i_{p}}{2}$ from equation 13. An alternative is to solve equation 9 according to variable $\mathrm{X}$, and use equation $\mathbf{1 1}$ to obtain an approximation of FWHM.

$\Psi_{\text {FWHM }}=\frac{\Psi_{\mathrm{p}}}{2}=\frac{1}{8-4 \mathrm{~B}}=\frac{\exp (\mathrm{X})}{(1+\exp (\mathrm{X}))^{2}-2 \mathrm{~B} \exp (\mathrm{X})}=\frac{\chi}{(1+\chi)^{2}-2 \mathrm{~B} \chi} \quad$ with $\chi=\exp (\mathrm{X})$ $\chi^{2}+2(B-3) \chi+1=0$

$\left\{\begin{array}{l}\chi_{+}=(3-\mathrm{B})+\sqrt{\mathrm{B}^{2}-6 \mathrm{~B}+8} \\ \chi_{-}=(3-\mathrm{B})-\sqrt{\mathrm{B}^{2}-6 \mathrm{~B}+8}\end{array} \quad\right.$ and $\quad\left\{\begin{array}{l}\mathrm{X}_{+}=\ln \left((3-\mathrm{B})+\sqrt{\mathrm{B}^{2}-6 \mathrm{~B}+8}\right) \\ \mathrm{X}_{-}=\ln \left((3-\mathrm{B})-\sqrt{\mathrm{B}^{2}-6 \mathrm{~B}+8}\right)\end{array}\right.$

The symmetry of $\mathrm{I}-\mathrm{E}$ curve at $\mathrm{E}=\mathrm{E}_{\mathrm{p}}(\mathrm{i} . \mathrm{e} . \mathrm{X}=0)$ imposes that $\mathrm{X}_{+}=-\mathrm{X}_{-}$and leads to:

$\mathrm{X}_{+}=-\mathrm{X}_{-}=\ln \left((3-\mathrm{B})+\sqrt{\mathrm{B}^{2}-6 \mathrm{~B}+8}\right)=\ln \left(\frac{1+\sqrt{\frac{\mathrm{B}-2}{\mathrm{~B}-4}}}{1-\sqrt{\frac{\mathrm{B}-2}{\mathrm{~B}-4}}}\right)$

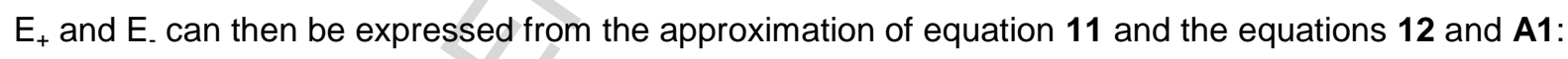

$$
\left\{\begin{array} { l } 
{ X _ { + } = \operatorname { l n } ( \frac { 1 + \sqrt { \frac { B - 2 } { B - 4 } } } { 1 - \sqrt { \frac { B - 2 } { B - 4 } } } ) = \frac { n F } { R T } ( E _ { + } - E _ { p } ) \lambda } \\
{ X _ { - } = - \operatorname { l n } ( \frac { 1 + \sqrt { \frac { B - 2 } { B - 4 } } } { 1 - \sqrt { \frac { B - 2 } { B - 4 } } } ) = \frac { n F } { R T } ( E _ { - } - E _ { p } ) \lambda }
\end{array} \Rightarrow \left\{\begin{array}{l}
E_{+}=\frac{R T}{n F \lambda} \ln \left(\frac{1+\sqrt{\frac{B-2}{B-4}}}{1-\sqrt{\frac{B-2}{B-4}}}\right)+E p \\
E_{-}=-\frac{R T}{n F \lambda} \ln \left(\frac{1+\sqrt{\frac{B-2}{B-4}}}{1-\sqrt{\frac{B-2}{B-4}}}\right)+E p
\end{array}\right.\right.
$$

From equation A2, FWHM and its standard deviation can be deduced: 


$$
\begin{aligned}
& \mathrm{FWHM}=\mathrm{E}_{+}-\mathrm{E}_{-}=2 \frac{\mathrm{RT}}{\mathrm{nF} \lambda} \ln \left(\frac{1+\sqrt{\frac{\mathrm{B}-2}{\mathrm{~B}-4}}}{1-\sqrt{\frac{\mathrm{B}-2}{\mathrm{~B}-4}}}\right)=2 \frac{\mathrm{RT}}{\mathrm{nF}}(1-\gamma \mathrm{B}) \ln \left(\frac{1+\sqrt{\frac{\mathrm{B}-2}{\mathrm{~B}-4}}}{1-\sqrt{\frac{\mathrm{B}-2}{\mathrm{~B}-4}}}\right) \\
& \sigma_{\mathrm{FWHM}}=2 \frac{\mathrm{RT}}{\mathrm{nF}}\left(\gamma \ln \left(\frac{1+\sqrt{\frac{\mathrm{B}-2}{\mathrm{~B}-4}}}{1-\sqrt{\frac{\mathrm{B}-2}{\mathrm{~B}-4}}}\right)+\frac{2(1-\gamma \mathrm{B})}{(\mathrm{B}-4)^{2} \sqrt{\frac{\mathrm{B}-2}{\mathrm{~B}-4}}\left(1+\sqrt{\frac{\mathrm{B}-2}{\mathrm{~B}-4}}\right)\left(1-\sqrt{\frac{\mathrm{B}-2}{\mathrm{~B}-4}}\right)}\right) \sigma_{\mathrm{B}}
\end{aligned}
$$




\section{References}

[1] W.A. Zisman, W.C. Bigelow, D.L. Pickett, Oleophobic monolayers.1. Films adsorbed from solution in nonpolar liquids, Journal of Colloid Science, 1 (1946) 513-538.

[2] J.C. Love, L.A. Estroff, J.K. Kriebel, R.G. Nuzzo, G.M. Whitesides, Self-assembled monolayers of thiolates on metals as a form of nanotechnology, Chemical Reviews, 105 (2005) 1103-1169.

[3] A.L. Eckermann, D.J. Feld, J.A. Shaw, T.J. Meade, Electrochemistry of redox-active self-assembled monolayers, Coordin Chem Rev, 254 (2010) 1769-1802.

[4] E. Laviron, Adsorption, autoinhibition and autocatalysis in polarography and in linear potential sweep voltammetry, Journal of Electroanalytical Chemistry and Interfacial Electrochemistry, 52 (1974) 355-393.

[5] E. Laviron, General expression of the linear potential sweep voltammogram in the case of diffusionless electrochemical systems, Journal of Electroanalytical Chemistry and Interfacial Electrochemistry, 101 (1979) 19-28.

[6] O. Aleveque, P.Y. Blanchard, C. Gautier, M. Dias, T. Breton, E. Levillain, Electroactive self-assembled monolayers: Laviron's interaction model extended to non-random distribution of redox centers,

Electrochemistry Communications, 12 (2010) 1462-1466.

[7] O. Aleveque, E. Levillain, Electroactive mixed self-assembled monolayers: Lateral interactions model updated to interactions between redox and non-redox species, Electrochemistry Communications, 34 (2013) 165-169.

[8] E. Laviron, Surface linear potential sweep voltammetry, Journal of Electroanalytical Chemistry and Interfacial Electrochemistry, 52 (1974) 395-402.

[9] W. Huang, T.L.E. Henderson, A.M. Bond, K.B. Oldham, Curve-fitting to resolve overlapping voltammetric peaks - model and examples, Analytica Chimica Acta, 304 (1995) 1-15.

[10] M. Palys, T. Korba, M. Bos, W.E. Vanderlinden, The separation of overlapping peaks in cyclic voltammetry by means of semi-differential transformation, Talanta, 38 (1991) 723-733.

[11] L.Y.S. Lee, R.B. Lennox, Electrochemical desorption of n-alkylthiol SAMs on polycrystalline gold: Studies using a ferrocenylalkylthiol probe, Langmuir, 23 (2007) 292-296.

[12] L.Y.S. Lee, T.C. Sutherland, S. Rucareanu, R.B. Lennox, Ferrocenylalkylthiolates as a probe of heterogeneity in binary self-assembled monolayers on gold, Langmuir, 22 (2006) 4438-4444.

[13] H.H. Tian, Y. Dai, H.B. Shao, H.Z. Yu, Modulated Intermolecular Interactions in Ferrocenylalkanethiolate Self-Assembled Monolayers on Gold, Journal of Physical Chemistry C, 117 (2013) 1006-1012.

[14] O. Alévêque, E. Levillain, Electroactive self-assembled monolayers: A versatile function to fit symmetric voltammetric peak, Electrochemistry Communications, 51 (2015) 137-143.

[15] P.-Y. Blanchard, O. Aleveque, S. Boisard, C. Gautier, A. El-Ghayoury, F. Le Derf, T. Breton, E. Levillain, Intermolecular interactions in self-assembled monolayers of tetrathiafulvalene derivatives, Physical

Chemistry Chemical Physics, 13 (2011) 2118-2120. 
A generalized lateral interactions function to fit voltammetric peaks of self-assembled monolayers.

Olivier Alévêque* and Eric Levillain

Université d'Angers, CNRS UMR 6200, Laboratoire MOLTECH-Anjou, 2 bd Lavoisier, 49045 ANGERS cedex, France.

* Corresponding authors: Tel.: (+33)241735090; Fax: (+33)241735405

E-mail address: olivier.aleveque@univ-angers.fr (Olivier ALEVEQUE)

FIGURES 

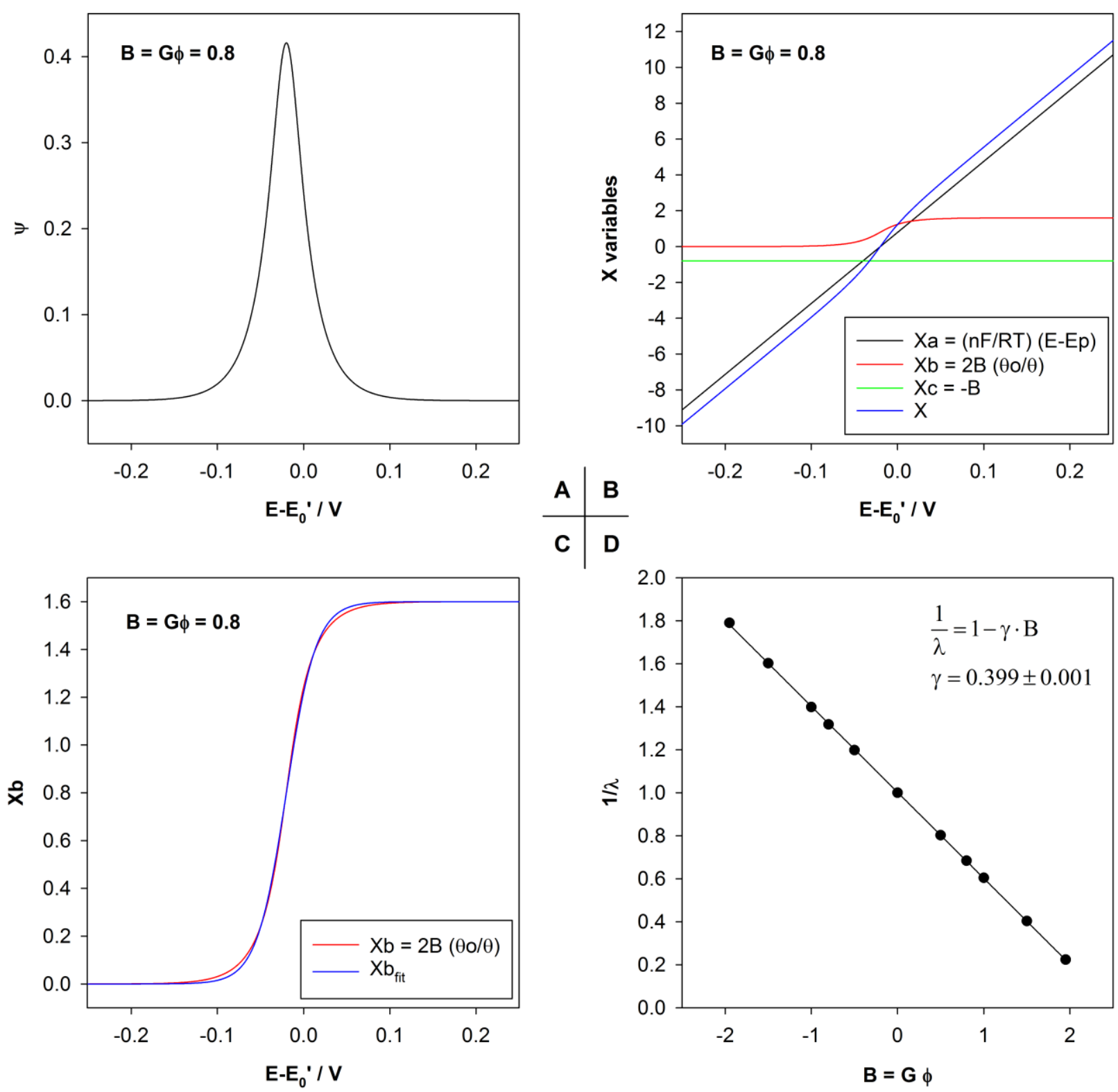

Figure 1.

(A) Dimensionless simulated current of a SAM vs. $\left(E-E_{0}{ }^{\prime}\right)$ using $B=G \phi=0.8$ (and $S \phi=-0.8$ ).

(B) Decomposition of the different components of the variable $X(X=X a+X b+X c)$ vs. $\left(E-E_{0}{ }^{\prime}\right)$ in the case of the simulation performed in A).

(C) $\mathrm{Xb}$ component (red) and fitted curve of $\mathrm{Xb}$ component (blue) using a generalized sigmoid vs. ( $\mathrm{E}^{-\mathrm{E}_{0}}$ ) in the case of the simulation performed in A).

(D) $\lambda$ parameter of generalized sigmoids extracted from a set of simulations vs. B parameter. 

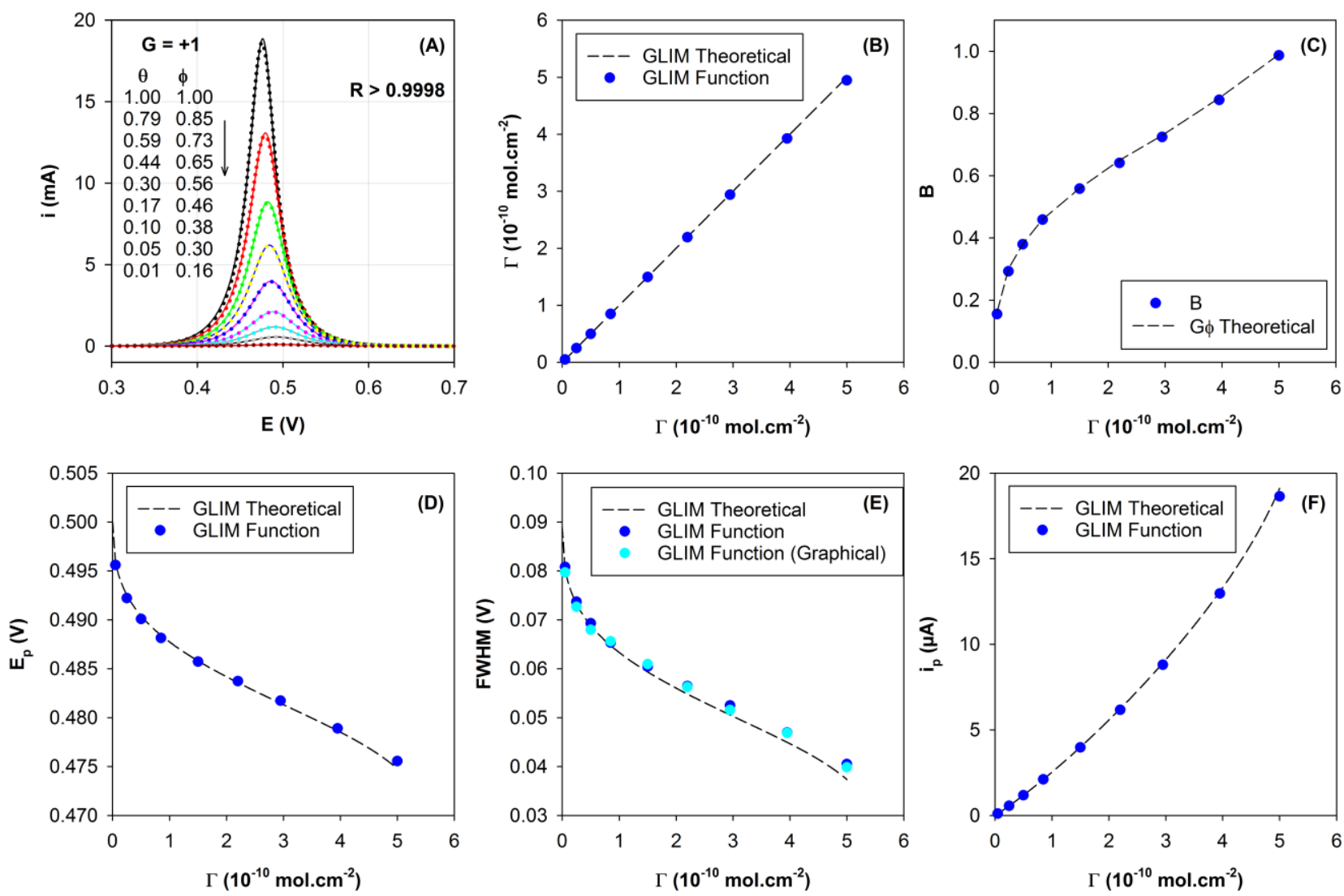

Figure 2.

Evaluation of GLI function peak fitting on simulated CVs from GLI model in the case of full reversible reaction $\left(\frac{\mathrm{k}}{\mathrm{V}} \rightarrow \infty, \mathrm{n}=1, \mathrm{k}=1000 \mathrm{~s}^{-1}, \mathrm{E}_{0^{\prime}}=0.500 \mathrm{~V}, \mathrm{~T}=293 \mathrm{~K}, \mathrm{v}=0.1 \mathrm{~V} \cdot \mathrm{s}^{-1}, \mathrm{~A}=0.2 \mathrm{~cm}^{2}\right.$ and $\left.\Gamma_{\max }=510^{-10} \mathrm{~mol} . \mathrm{cm}^{2}\right)$ in the case of $\mathrm{G}=+1$ and $\mathrm{S}=-1$.

(A) (lines) simulated CVs with different values of surface coverage $(\theta)$ and phase segregation $(\phi)$, and (dotted lines) fitted curves using GLI function.

Comparison of $(---)$ theoretical, $(\bullet)$ fitted and $(\bullet)$ graphically estimated parameters: (B) surface coverage, (C) B parameter, (D) peak potential, (E) full width at half maximum and $(F)$ peak intensity 

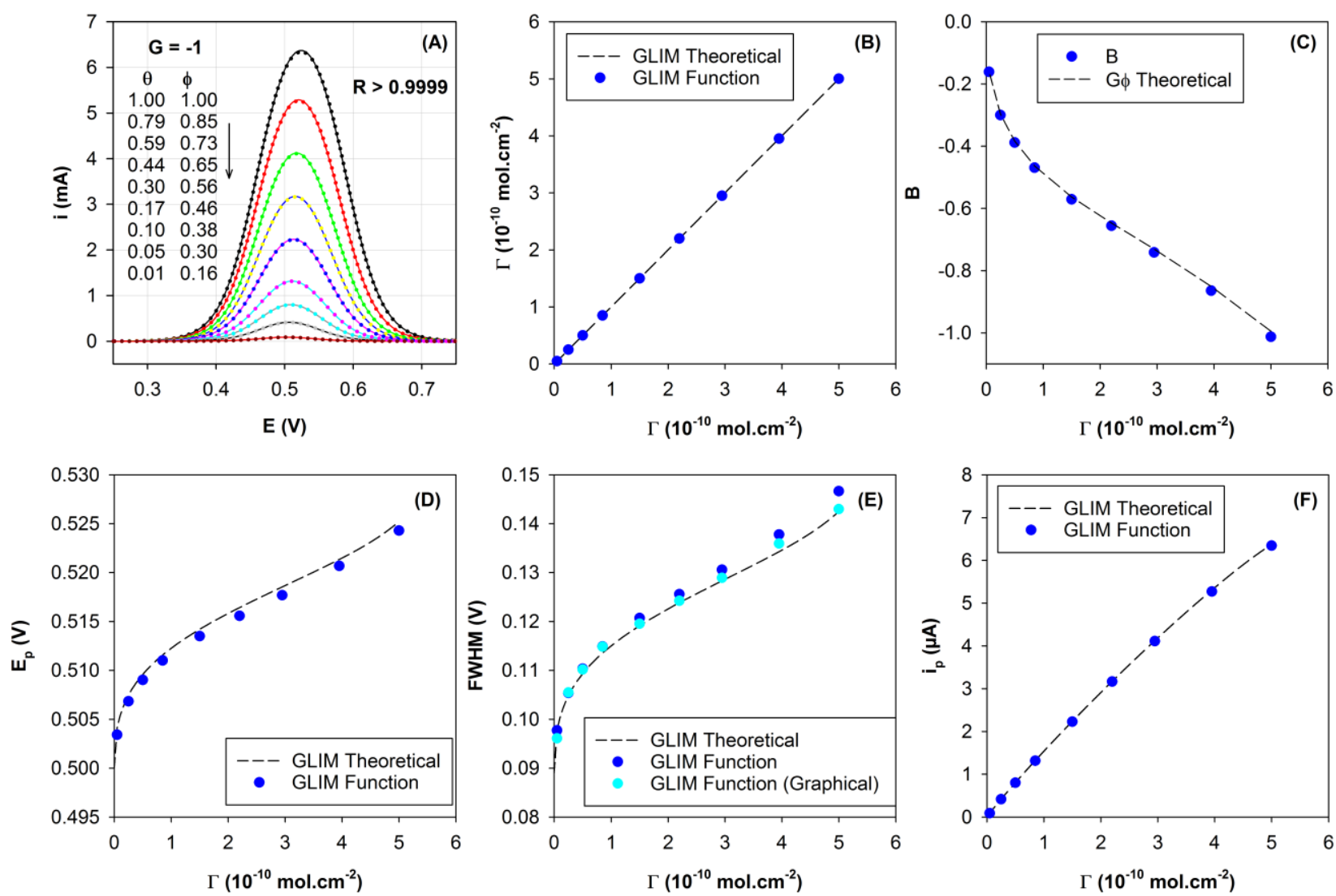

Figure 3.

Evaluation of GLI function peak fitting on simulated CVs from GLI model in the case of full reversible reaction $\left(\frac{\mathrm{k}}{\mathrm{V}} \rightarrow \infty, \mathrm{n}=1, \mathrm{k}=1000 \mathrm{~s}^{-1}, \mathrm{E}_{0^{\prime}}=0.500 \mathrm{~V}, \mathrm{~T}=293 \mathrm{~K}, \mathrm{v}=0.1 \mathrm{~V} \cdot \mathrm{s}^{-1}, \mathrm{~A}=0.2 \mathrm{~cm}^{2}\right.$ and $\left.\Gamma_{\max }=510^{-10} \mathrm{~mol} \cdot \mathrm{cm}^{2}\right)$ in the case of $G=-1$ and $S=+1$.

(A) (lines) simulated CVs with different values of surface coverage $(\theta)$ and phase segregation $(\phi)$, and (dotted lines) fitted curves using GLI function.

Comparison of $(---)$ theoretical, $(\bullet)$ fitted and $(\bullet)$ graphically estimated parameters: (B) surface coverage, (C) B parameter, (D) peak potential, (E) full width at half maximum and $(F)$ peak intensity 

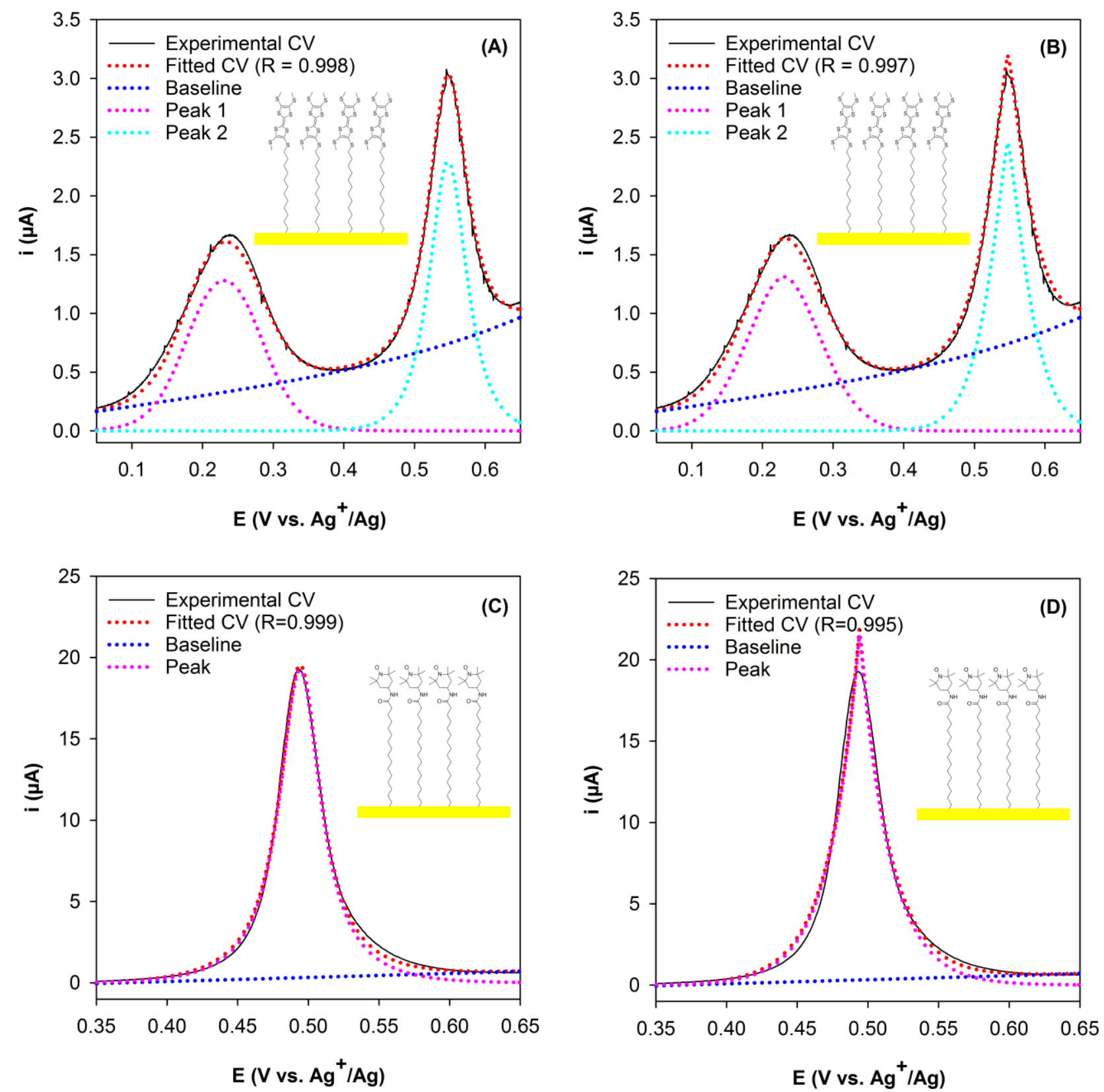

Figure 4.

Evaluation of GLI function peak fitting on experimental CV of TTF [15] and TEMPO [6] SAMs in $0.1 \mathrm{M}$ $\mathrm{Bu}_{4} \mathrm{NPF}_{6} / \mathrm{CH}_{2} \mathrm{Cl}_{2}$, at 0.1 V.s s $^{-1}$ and $293 \mathrm{~K}$, and comparison to Generalized Gaussian (GG) function peak fitting.

(A) Electrochemical parameters deduced of two peaks fitting using GLI function on TTF SAM: $\Gamma=0.8910^{-10} \mathrm{~mol}_{\mathrm{cm}} \mathrm{cm}^{-2} \mathrm{~B}_{1}=-0.659, \mathrm{E}_{\mathrm{p} 1}=0.231 \mathrm{~V}, \mathrm{FWHM}_{1}=0.126 \mathrm{~V}, \mathrm{i}_{\mathrm{p} 1}=1.2810^{-6} \mathrm{~A}, \mathrm{E}_{\mathrm{p} 2}=0.547 \mathrm{~V}, \mathrm{~B}_{2}=$ $0.516, \mathrm{FWHM}_{2}=0.062 \mathrm{~V}, \mathrm{i}_{\mathrm{p} 2}=2.2910^{-6} \mathrm{~A}$

(B) Electrochemical parameters deduced of two peaks fitting using GG function on TTF SAM:

$\Gamma=0.9010^{-10} \mathrm{~mol}_{\mathrm{cm}} \mathrm{cm}^{-2}, \mathrm{E}_{\mathrm{p} 1}=0.231 \mathrm{~V}, \mathrm{FWHM}_{1}=0.122 \mathrm{~V}, \mathrm{i}_{\mathrm{p} 1}=1.3110^{-6} \mathrm{~A}$,

$\mathrm{E}_{\mathrm{p} 2}=0.547 \mathrm{~V}, \mathrm{FWHM}_{2}=0.057 \mathrm{~V}, \mathrm{i}_{\mathrm{p} 2}=2.4610^{-6} \mathrm{~A}$.

(C) Electrochemical parameters deduced of two peaks fitting using GLI function on TEMPO SAM:

$\Gamma=4.6810^{-10} \mathrm{~mol}_{\mathrm{cm}} \mathrm{cm}^{-2}, \mathrm{~B} 1=1.071, \mathrm{E}_{\mathrm{p} 1}=0.4940 \mathrm{~V}, \mathrm{FWHM}_{1}=0.037 \mathrm{~V}, \mathrm{i}_{\mathrm{p} 1}=19.2610^{-6} \mathrm{~A}$

(D) Electrochemical parameters deduced of two peaks fitting using GG function on TEMPO SAM: $\Gamma=4.7710^{-10} \mathrm{~mol}_{\mathrm{cm}} \mathrm{cm}^{-2}, \mathrm{E}_{\mathrm{p} 1}=0.494 \mathrm{~V}, \mathrm{FWHM}_{1}=0.029 \mathrm{~V}, \mathrm{i}_{\mathrm{p} 1}=21.7310^{-6} \mathrm{~A}$ 

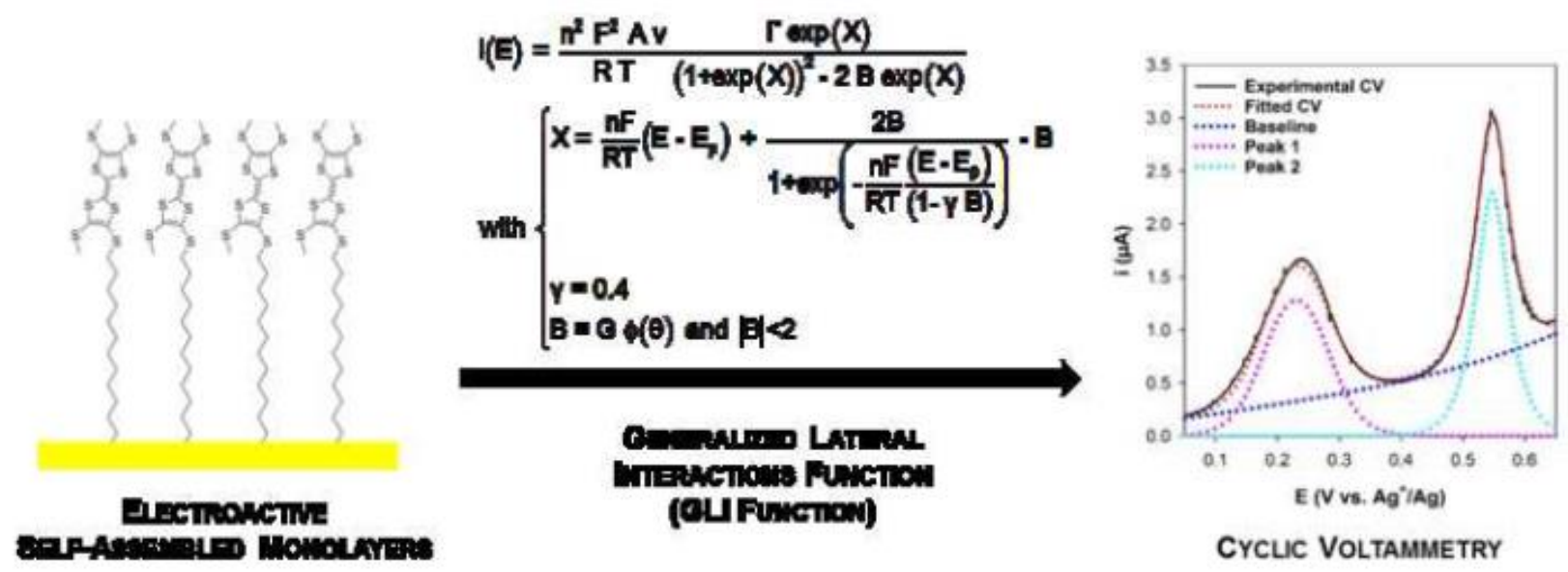

CYCLIC VOLTAMMETRY

Graphical abstract 


\section{Highlights}

- A function derived from a theoretical model fits adsorption voltammetric peak.

- This approach is dedicated to SAMs where interactions between electroactive centers are possible.

- The fitting procedure is easy to implement and gives access to characteristic parameters of a voltammetric peak (i.e. $E_{p}, i_{p}, F W H M, \Gamma$, and interaction parameter). 